\title{
3D analysis of solid reinforced concrete beams subjected to combined load of bending, torsion and shear
}

\author{
A. S. Alnuaimi \\ Civil and Architectural Engineering, Sultan Qaboos University, \\ Sultanate of Oman
}

\begin{abstract}
This paper presents a comparison between experimental and an in house 3-D finite element analysis results of three reinforced concrete solid beams subjected to combined loadings of bending, shear and torsion. The finite element program adopted was based on a 20 node isoparametric element. A non-linear elastic isotropic model, proposed by Kotsovos, was used to model concrete behaviour, while steel was modelled as an embedded element exhibiting elastic-perfectly plastic response. Allowance was made for shear retention and for tension stiffening in concrete after cracking. Only fixed direction, smeared cracking modelling was adopted. The beam dimensions were $300 \times 300 \mathrm{~mm}$ cross section, $3800 \mathrm{~mm}$ length. Experimental results were compared with the non-linear predictions. The comparison was judged by load displacement relationship, steel strain, and load and mode of failure. Good agreement was observed between predicted ultimate and experimentally measured loads. It was concluded that the present program can confidently be used to predict the behaviour and failure load of reinforced concrete solid beams subjected to combined load of bending, torsion and shear.
\end{abstract}

Keywords: beam, solid beam, bending, shear, torsion, direct design, concrete, reinforced concrete, stress analysis, combined loading.

\section{Introduction}

The behaviour of solid beams when subjected to combined loading is very complex. A detailed analysis would normally require a three-dimensional finite element model. Rahal and Collins [1] developed a three-dimensional analytical 
model capable of analysing rectangular sections subjected to combined loading of biaxial bending, biaxial shear, torsion and axial load. The model takes into account the shear-torsion interaction and concrete spalling. It idealizes the rectangular cross-section resisting shear and torsion as made of four transversely reinforced walls with varying thickness and varying angle of principal compressive strains. The vertical shear stress due to shear force is uniformly resisted by the vertical walls and the lateral shear stress is resisted by the horizontal walls. They tested their model and concluded that the model predicts very close results to experimental behavioural and ultimate load results. Ibell et al [2] used an upper-bound plasticity analysis in a 2D model for the assessment of shear in reinforced concrete beams. The results from this model were compared with experimental results. It was recommended that the $2 \mathrm{D}$ analysis to be extended to more general 3D collapse analysis. Rabczuk and Eibl [3] presented a model using a mesh free 2D Galerkin/ finite element approach. The concrete was modelled with particles and reinforcement with beam element. For steel, an elastoplastic constitutive law with isotropic hardening and tension cut-off was used. The concrete was modelled via a continuum damage model, where an anisotropic tensile damage variable was used to capture the behaviour of concrete in tension. They used a displacement controlled approach for testing their model. They compared the results from their model with experimental results from one rectangular and one I-section pre-stressed beams. They concluded that a full 3D simulation would be more appropriate.

In this research an in-house 3-D finite element program was used for nonlinear analysis of this computational study. The program was developed by ElNuonu [4] using Kotsovs' concrete model. This model was based on experimental data obtained at Imperial College London from tests on the behaviour of concrete under complex stress states (Kotsovos and Newman [5] and Kotsovos [6]). The testing techniques used to obtain this data were validated by comparing them with those obtained in an international co-operative programme of research into the effect of different test methods on the behaviour of concrete. This model is capable of describing the behaviour of concrete under uniaxial, biaxial and triaxial stress conditions. It requires only the concrete cube compressive strength $f_{c u}$ to define the behaviour of concrete under different stress states. More information about this model is given in Kotsovos and Pavlovic [7].

\section{A 3D finite element program}

In the $3 \mathrm{D}$ program, a $150 \times 150 \times 150 \mathrm{~mm}$ iso-parametric solid element with twenty node and twenty seven Gauss points was used. The concrete cylinder compressive strength $f_{c}^{\prime}$ is taken as $f^{\prime}{ }^{\prime}=0.8 f_{\text {cu }} \mathrm{N} / \mathrm{mm}^{2}$, the Young's modulus $E_{\mathrm{c}}=5000 \sqrt{f_{c}^{\prime}} \mathrm{N} / \mathrm{mm}^{2}$, the split cylinder tensile strength $f_{t}^{\prime}=0.54 \sqrt{f_{c}^{\prime}} \mathrm{N} / \mathrm{mm}^{2}$ and the Poisson's ratio was set at a constant value of 0.15 . Before cracking or crushing, the concrete behaviour is assumed to be non-linear elastic isotropic. 
Crushing occurs at a point when all the three principal stresses are compressive and the state of stress is on the 'yield' surface. In the case of concrete crushing, complete loss of strength is assumed i.e. no compression softening is allowed for. When the concrete cracks in any direction, concrete ceases to be isotropic and cracking can occur if the minimum principal strain (compressive) reaches a value taken as equal to 0.003 . After cracking, smeared crack approach with simple tension stiffening and shear retention equations are employed to represent the post cracking behaviour of concrete. Cracks are assumed to be orthogonal and once formed remain in their direction. The stress-strain relationship in tension was assumed to be linear up to $f_{t}^{\prime}$ and immediately after cracking the tensile stress $f_{t}$ is reduced to $0.8 f_{t}^{\prime}$. Thereafter, $f_{t}$ decreases linearly with strain and is zero at the maximum strain of 0.003 which roughly corresponds to yield strain of steel of 0.0025 . Transfer of shear stresses across cracks is modelled by means of the 'shear retention' factor $\beta$ which defines the shear modulus of cracked concrete as $\beta G$, where $G$ is the elastic shear modulus of the un-cracked concrete. The shear retention factor $\beta=1.0$ if $\varepsilon_{\mathrm{n}} \leq \varepsilon_{\mathrm{cr}}$ and $\beta=0.25 \varepsilon_{\mathrm{cr}} / \varepsilon_{\mathrm{n}}$ if $\varepsilon_{\mathrm{n}}>\varepsilon_{\mathrm{cr}}$, where $\varepsilon_{\mathrm{cr}}=$ cracking strain $\left(\varepsilon_{c r}=f_{t}^{\prime} / E_{c}\right)$ and $\varepsilon_{\mathrm{n}}=$ average of the three principal strains at any cracked point $\left(\varepsilon_{n}=\left(\varepsilon_{1}+\varepsilon_{2}+\varepsilon_{3}\right) / 3\right)$. The reinforcement is modelled as one dimensional element embedded in the solid concrete elements. Elastic-plastic stress-strain behaviour without strain hardening was used in this research. Only uniaxial resistance is considered with no provision for kinking or dowel action of bars.

Standard incremental-iterative procedure was adopted for solution. The load increments were equal to $10 \%$ of the design load for the first three increments and $5 \%$ for the remaining increments. The maximum number of increments was 50 and the maximum number of iterations in each increment was 200. The convergence being deemed satisfactory if the ratio of the square roots of the sum of the squares of the residual forces to that of the applied loads did not exceed $5 \%$.

The stresses in the cross-section nearest to mid-span were analysed. The stress distribution at the last converged increment was used for the analysis. In deciding on the predicted mode of failure, the load-deflection relationship, steel strain and ultimate load were taken into consideration. The program was extensively used by Bhatt and Lim for the analysis of slabs, internal column-flat slab junctions and punching shear failure of flat slabs (Bhatt and Lim [8,9]). Good agreement between predicted and experimental results was found.

\section{Tested beams}

Three reinforced concrete beams tested by Alnuaimi and Bhatt [10] were analysed. All beams were 300x300mm cross section and $3.8 \mathrm{~m}$ length. They were subjected to combined load of bending, torsion and shear (Table 1). The main variables studied were the ratio of the shear stress due to torsion to shear stress 
due to shear force $\tau_{\text {tor }} / \tau_{\text {shr }}$ which varied between 0.69 and 3.04 and the ratio of the torsion to bending moment $\mathrm{T}_{\mathrm{d}} / \mathrm{M}_{\mathrm{d}}$ which varied between 0.26 and 1.19.

The concrete mix consisted of cement, uncrushed $10 \mathrm{~mm}$ gravel and sand with water/ cement ratio of 0.55 . Three cubes, $100 \times 100 \times 100 \mathrm{~mm}$, and six cylinders, $150 \times 300 \mathrm{~mm}$, for each beam were cast from the same concrete used for casting each beam. The specimen and the samples were kept under damp Hessian for about four days and then under room condition. The samples were tested on the day the beam was tested to determine the cube and cylinder compressive strengths and split cylinder tensile strength of concrete.

Table 1: Load combination.

\begin{tabular}{|l|c|c|c|c|c|c|c|}
\hline \multirow{2}{*}{$\begin{array}{l}\text { Beam } \\
\text { No. }\end{array}$} & $\mathrm{T}_{\mathrm{d}}$ & $\mathrm{M}_{\mathrm{d}}$ & $\mathrm{V}_{\mathrm{d}}$ & $\tau_{\text {tor }}$ & $\tau_{\text {shr }}$ & $\mathrm{T}_{\mathrm{d}} / \mathrm{M}_{\mathrm{d}}$ & $\tau_{\text {tor }} / \tau_{\text {shr }}$ \\
\cline { 2 - 8 } & $\mathrm{kNm}$ & $\mathrm{kNm}$ & $\mathrm{kN}$ & $\mathrm{N} / \mathrm{mm}^{2}$ & $\mathrm{~N} / \mathrm{mm}^{2}$ & Ratio & Ratio \\
\hline BTV13 & 26 & 50.89 & 61.08 & 4.16 & 3.00 & 0.51 & 1.39 \\
\hline BTV14 & 13 & 50.89 & 61.08 & 2.08 & 3.00 & 0.26 & 0.69 \\
\hline BTV15 & 39 & 32.89 & 41.08 & 6.24 & 2.05 & 1.19 & 3.04 \\
\hline
\end{tabular}

Table 2 shows the average yield strengths of reinforcement and compressive and tensile strengths of concrete. The concrete cube and cylinder compressive strengths shown for each beam in Table 2 are the measured average strengths of the three cubes and three cylinders respectively and the concrete tensile strength shown is the measured average strength of three cylinders tested for split test. All results were obtained from samples cured along side each beam.

Table 2: $\quad$ Average material properties.

\begin{tabular}{|c|c|c|c|c|c|}
\hline \multirow{2}{*}{ Beam No. } & $\mathrm{f}_{\mathrm{cu}}$ & $\mathrm{f}_{\mathrm{c}}$ & $\mathrm{f}^{{ }{ }_{\mathrm{t}}}$ & $\mathrm{f}_{\mathrm{y}}$ & $\mathrm{f}_{\mathrm{yv}}$ \\
\cline { 2 - 6 } & $\mathrm{N} / \mathrm{mm}^{2}$ & $\mathrm{~N} / \mathrm{mm}^{2}$ & $\mathrm{~N} / \mathrm{mm}^{2}$ & $\mathrm{~N} / \mathrm{mm}^{2}$ & $\mathrm{~N} / \mathrm{mm}^{2}$ \\
\hline BTV13 & 40 & 28.5 & 3.45 & 500 & 500 \\
\hline BTV14 & 37 & 25.7 & 2.92 & 500 & 500 \\
\hline BTV15 & 61 & 38.2 & 4.38 & 500 & 500 \\
\hline
\end{tabular}

Figure 1 shows the provided reinforcement and arrangement of longitudinal bars for each beam. The solid circles in Figure 1 represent the longitudinal bars in which strain was measured nearest to mid-span. Strains in the stirrups nearest to mid-span are also reported.

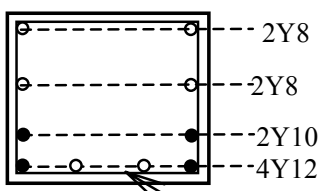

BTV13

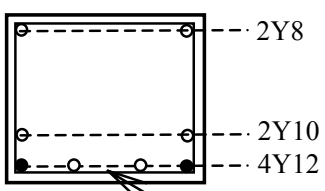

BTV14 Y

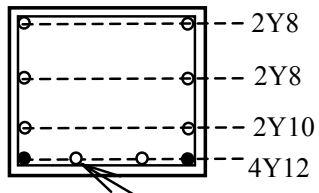

BTV15 Y8@82 mm

Figure 1: $\quad$ Provided reinforcement at test-span. 


\section{Test setup and instrumentation}

Figure 2 shows a testing rig with typical beam installed. The test rig is a threedimensional frame designed to allow application of torsion, bending moment and shear force. The model was mounted on two steel stools fixed to the concrete floor at a distance of $1.8 \mathrm{~m}$ a part. The test span was $1.2 \mathrm{~m}$ long centred at midspan. The beam was simply supported by a set of two perpendicular rollers at each support and a system of pin-and-roller at the mid-span of the top face. At the support, the lower roller allows axial displacement and the upper one allows rotation about a horizontal axis at the soffit level of the beam. Torsion was applied by means of a torsion arm fixed to each end of the beam while bending moment and shear force were a result of applied load at mid-span across the beam width at the top face. This support and loading arrangement allowed full rotation about the centre line of the beam soffit and displacement in the beam axial direction. It produced constant torsional shear stress over the entire length of the beam and maximum normal stress due to bending and shear stress due to shear force occurred near the mid-span. The load was measured using a data logger for data acquisition. Linear voltage displacement transducers (LVDT) were used to measure the vertical displacement at the bottom face of the beam. To measure strain in the bars, a pair of strain gauges, $6 \mathrm{~mm}$ long, was fixed on directly opposite faces of the bar and connected to a data logger. Accordingly, the axial strain recorded at each load stage was taken as the average reading of both gauges. Crack width and crack development were measured by means of a crack width measuring microscope.

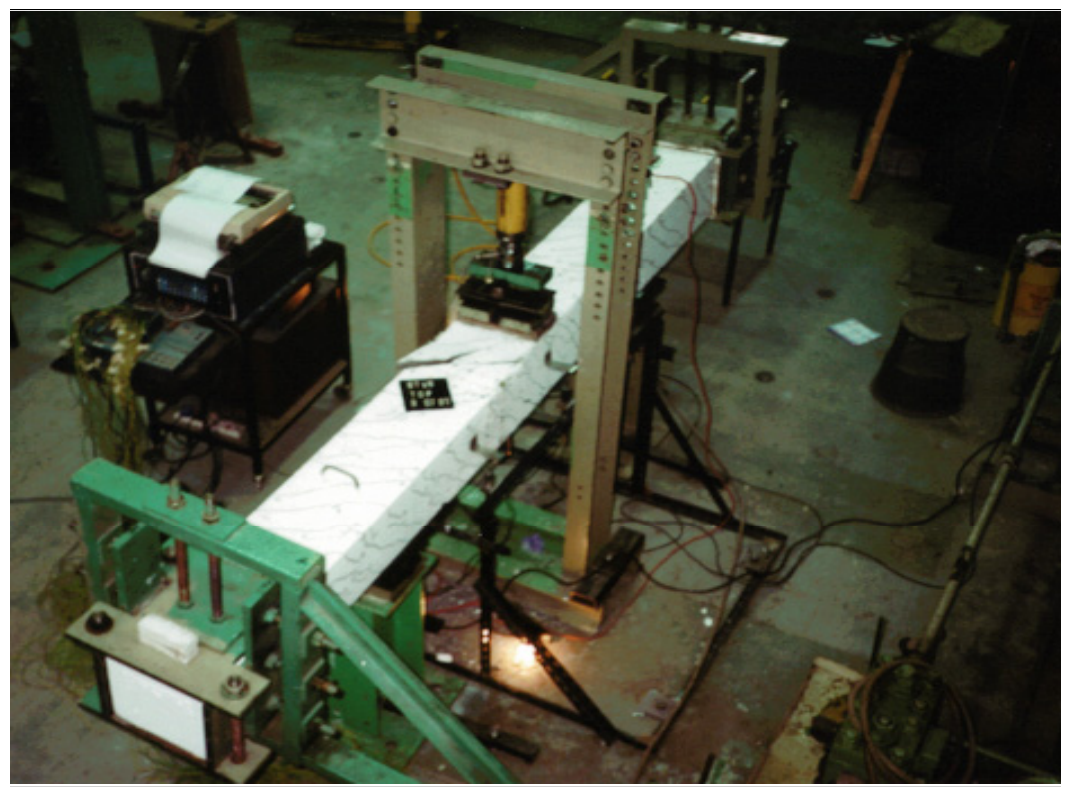

Figure 2: Test rig with a typical beam installation. 


\section{Comparison between experimental and computational results}

\subsection{Load displacement relationship}

Figure 3 shows the vertical measured and computed displacements at the centre of the bottom face of each beam. It is clear from this figure that, good agreement was achieved between experimental and computational results for beam BTV14. In the case of beams BTV13 the program predicted stiffer behaviour than the measured. The predicted and measured values from beams BTV15 were small and difficult to judge. The measured and computed displacements of beams BTV13 and BTV14 with bending dominance $\left(\mathrm{T}_{\mathrm{d}} / \mathrm{M}_{\mathrm{d}}<1\right)$ reached the displacement limit of span/250. Beam BTV15 with torsion dominance $\left(\mathrm{T}_{d} / \mathrm{M}_{d}>1\right)$ experienced measured and computed relatively smaller displacements and did not reach the span/250 limit.
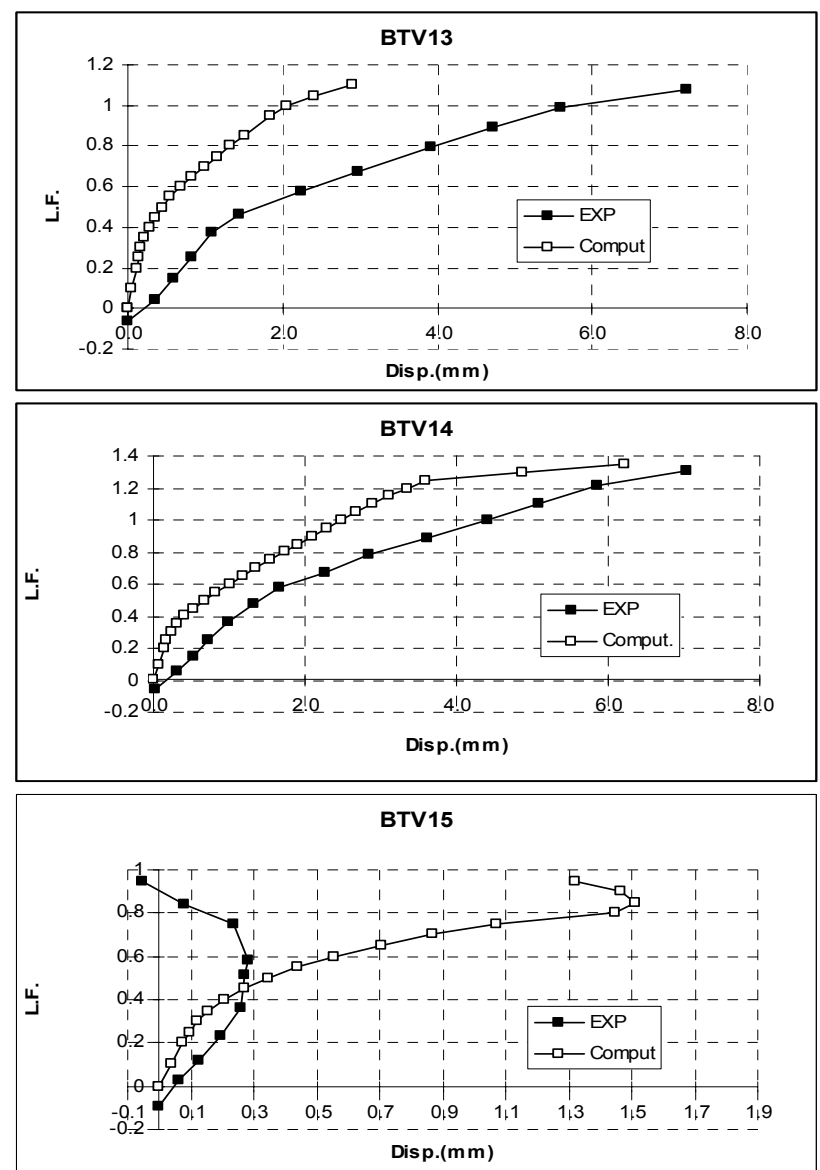

Figure 3: Vertical displacement at mid-span. 


\subsection{Strain in the longitudinal steel}

Figure 4 shows good agreement between the measured and computed strain ratios in the longitudinal steel. In beams BTV13 and BTV14 with $T_{d} / M_{d}<1$, the longitudinal steel yielded or reached yield strain while slightly less strain was recorded in beam BTV15 with $T_{d} / M_{d}>1$.

\subsection{Strain in the transverse steel}

Figure 5 shows strain ratios in the transverse steel; in general, a very good agreement between measured and computed results was achieved. The transverse steel yielded or reached near yield strain.
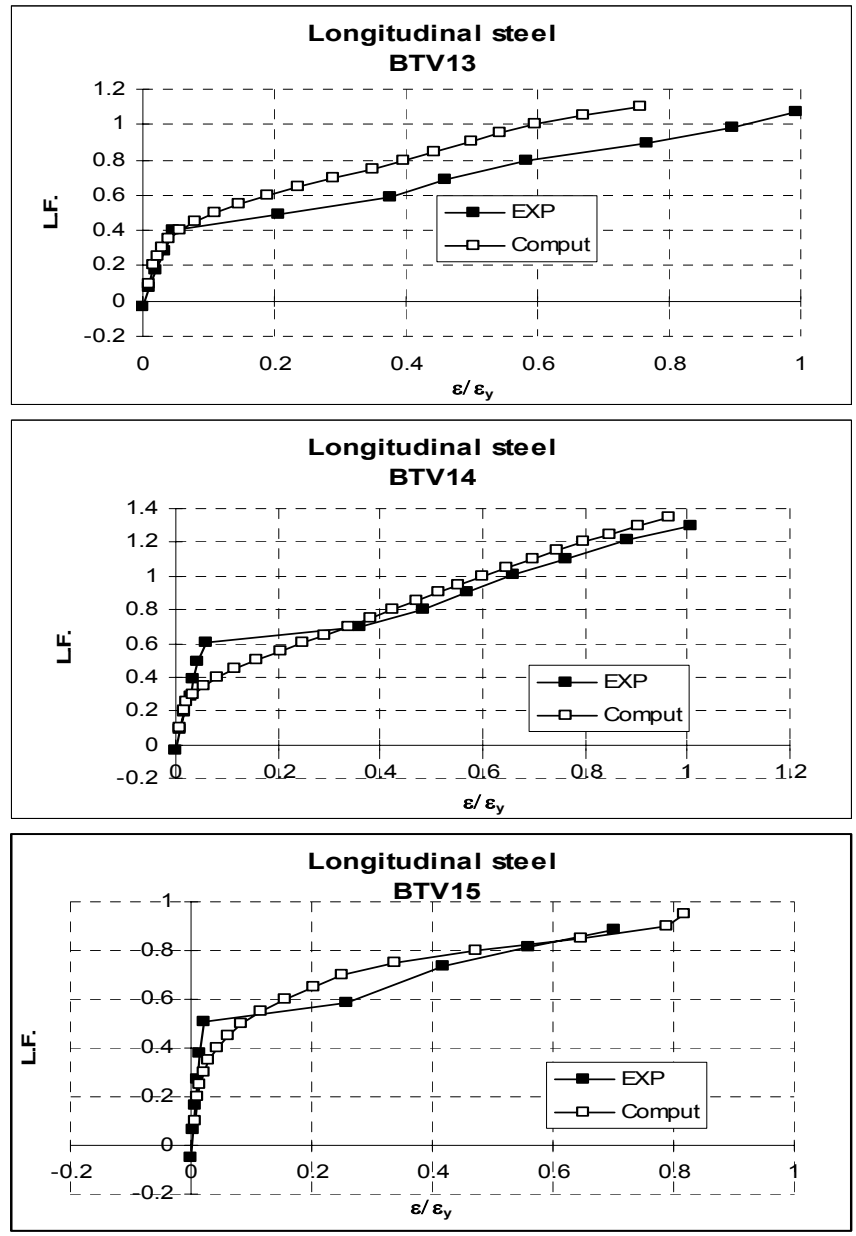

Figure 4: $\quad$ Strain ratios in the longitudinal steel. 

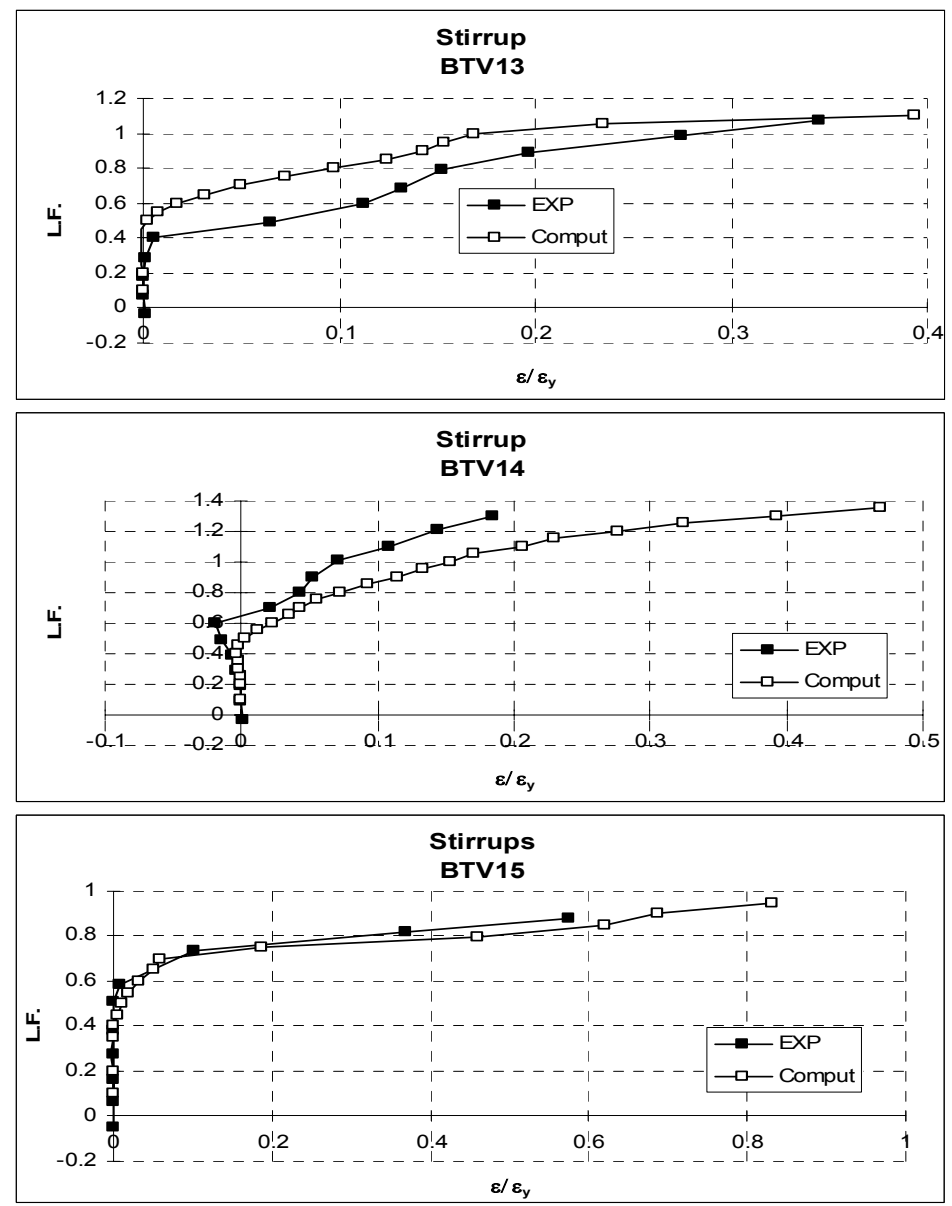

Figure 5: $\quad$ Strain ratios in the transverse steel.

\subsection{Failure load and mode of failure}

Column 4 of Table 3 shows very good agreement between the measured $\mathrm{L}_{\mathrm{e}}$ and computed $\mathrm{L}_{\mathrm{c}}$ failure loads. All beams failed near their design loads.

Both the computed and measured results showed that in the case of beams in which bending was dominant $\left(\mathrm{T}_{\mathrm{d}} / \mathrm{M}_{\mathrm{d}}<1\right)$ almost vertical cracks started in the bottom face and at the lower half of the front and rear sides. These cracks were followed by inclined cracks in succeeding load increments until they first appear in the top face at about $80 \%$ of failure load. In the beams where torsion was dominant $\left(\mathrm{T}_{\mathrm{d}} / \mathrm{M}_{\mathrm{d}}>1\right)$, inclined cracks extended into the bottom face one increment after they were formed in the front and rear sides. In both groups, the smaller the ratio $T_{d} / M_{d}$, the closer is the angle of crack to vertical. In beams 
BTV13, BTV14 the mode of failure was mostly flexural where the beam experienced relatively large displacement and the flexural steel yielded. A small number of large cracks caused failure at the time of flexural steel yielding. Beam BTV15 failed by diagonal cracking due to high torsional shear stress and the failure mode was less ductile with small displacement, less longitudinal steel strain and larger transverse steel strain than the bending dominant beams.

Table 3: $\quad$ Ratios of measured and predicted failure loads.

\begin{tabular}{|c|c|c|c|}
\hline 1 & 2 & 3 & 4 \\
\hline \multirow{2}{*}{ Beam No. } & $\mathrm{T}_{\mathrm{d}} / \mathrm{M}_{\mathrm{d}}$ & $\tau_{\text {tor }} / \tau_{\text {shr }}$ & $\mathrm{L}_{\mathrm{e}} / \mathrm{L}_{\mathrm{c}}$ \\
\cline { 2 - 4 } & Ratio & Ratio & Ratio \\
\hline BTV13 & 0.51 & 1.39 & 0.98 \\
\hline \multirow{2}{*}{ BTV14 } & 0.26 & 0.69 & 0.96 \\
\hline BTV15 & 1.19 & 3.04 & 0.93 \\
\hline
\end{tabular}

\section{Conclusion}

From the results presented in this paper it can be concluded that the 3-D finite element program was shown to be in a good agreement with the experimental results and therefore, proven to be a good tool for the prediction of beam behaviour and ultimate load of solid reinforced concrete beams subjected to combined load of bending, torsion and shear.

\section{References}

[1] Rahal K. N. and Collins M. P., Analysis of Sections Subjected to Combined Shear and Torsion - A Theoretical Model. ACI Structural Journal, Vol. 92, No. 4, July-August 1995, pp. 459-469.

[2] Ibell T. J., Morley C.T. and Middleton C.R., An Upper-bound Plastic Analysis for Shear. Magazine of Concrete Research, 50, No.1, March 1998, pp. 67-73.

[3] Rabczuk T. and Eibl J., Numerical analysis of prestressed concrete beams using a coupled element free Galerkin/finite approach, International Journal of Solid and Structures, v.41, n.3-4, February 2004, pp 10611080 .

[4] El-Nuonu G. F. R., Design of Shear Wall-Floor Slab Connections. Ph.D. thesis, University of Glasgow, 1985.

[5] Kotsovos M. D. and Newman J. B., A mathematical Description of the Deformation Behaviour of Concrete under Complex Loading. Magazine of Concrete Research, Vol. 31, No. 107, June 1979, pp.77-90.

[6] Kotsovos M. D., A Mathematical Description of the Strength Properties of Concrete under Generalized Stress. Magazine of Concrete Research, Vol. 31, No. 108, Sep. 1979, pp. 151-158.

[7] Kotsovos M. D. and Pavlovic M. N., Structural Concrete, Finite element analysis for limit-state design, Thomas Telford Publications, 1 Heron Quey, London E14 4JD, 1995. 
[8] Bhatt P. and Lim B. T., Flat Slab-Column Junctions with Shear and Moment Transfer: A Comparison between Finite Element Predictions and Experiments. Proc. of $7^{\text {th }}$ ACME Conference, University of Durham, (Ed. Bettes, P.) pp. $11-14,1999$.

[9] Bhatt P. and Lim B. T., Punching Shear Capacity of Internal Column-Flat Slab Junction with In-Plane Restraint: A Comparison between Finite Element Predictions and Experiments. Developments in Analysis and Design Using Finite Element Methods, Civil-Comp Press, (Ed. B.H.V. Topping), pp. $141-147,1999$.

[10] Alnuaimi A. S. and Bhatt P., Design of Reinforced Concrete Solid Beams, Structures and Buildings Journal, Thomas Telford Limited, v.159, n.4, August 2006, pp 197-216. 